\title{
Key features in the optical properties of tissue during and after radiofrequency ablation
}

Kalloor Joseph, Francis, Lanka, Pranav, Kruit, Hindrik, Konugolu Venkata Sekar, Sanathana, Farina, Andrea, et al.

Francis Kalloor Joseph, Pranav Lanka, Hindrik Kruit, Sanathana Konugolu Venkata Sekar, Andrea Farina, Rinaldo Cubeddu, Srirang Manohar, Antonio Pifferi, "Key features in the optical properties of tissue during and after radiofrequency ablation," Proc. SPIE 11216, Multiscale Imaging and Spectroscopy, 112160H (2 March 2020); doi: 10.1117/12.2546042

SPIE. Event: SPIE BiOS, 2020, San Francisco, California, United States 


\title{
Key features in the optical properties of tissue during and after radiofrequency ablation
}

\author{
Kalloor Joseph Francis ${ }^{\mathrm{a}}$, Pranav Lanka ${ }^{\mathrm{b}}$, Hindrik Kruit ${ }^{\mathrm{a}}$, Sanathana Konugolu Venkata Sekar ${ }^{\mathrm{b}}$, \\ Andrea Farina ${ }^{c}$, Rinaldo Cubeddu ${ }^{\mathrm{b}}$, Srirang Manohar ${ }^{\mathrm{a}}$, and Antonio Pifferi ${ }^{\mathrm{b}, \mathrm{c}}$ \\ ${ }^{a}$ Biomedical Photonic Imaging Group and Multi-Modality Medical Imaging Group, Technical \\ Medical Centre, University of Twente, Enschede The Netherlands \\ ${ }^{b}$ Polytechnic University of Milan, Department of Physics, Milan, Italy \\ ${ }^{\mathrm{c}}$ National Research Council, Institute of Photonics and of Nanotechnologies, Milan, Italy
}

\begin{abstract}
The change in the optical properties of tissue during thermal treatment can be potentially used to monitor procedures like Radiofrequency Ablation (RFA). We present key features in the optical absorption and scattering of tissue during the RFA procedure and during post-ablation cooling down to room temperature. We have used time-resolved diffuse optical spectroscopy for the measurement of the optical properties of tissue for the wavelengths from 650 to $1100 \mathrm{~nm}$. Ex vivo experiments were conducted using a clinical RFA system on bovine liver tissue. Measurements were performed for two temperatures $\left(70^{\circ} \mathrm{C}\right.$ and $\left.105^{\circ} \mathrm{C}\right)$. The following features were observed in the optical properties. First, there was a decrease in optical absorption and an increase in scattering during the treatment. With overtreatment, the absorption increased for initial part of the spectrum (until 910 $\mathrm{nm}$ ) and scattering decreased in comparison to normal treatment. Secondly, a redshift of the hemoglobin peak and blue shift around water peak was observed in the optical absorption. Finally, a new peak around $840 \mathrm{~nm}$ and a valley around $920 \mathrm{~nm}$ appeared with heating. When the tissue was allowed to cool down, most of the changes in the absorption around the water peak partially reversed including the blue shift and the valley around 920 nm. Additionally scattering decreased with cooling. Results show key features in the optical properties of tissue during RFA, the effect of overtreatment and post-treatment cooling in ex vivo tissue. Insights from this study will help in advancing optical methods in monitoring thermal treatment.
\end{abstract}

Keywords: Optical properties, thermal treatment, radiofrequency ablation, spectroscopy

\section{INTRODUCTION}

Radiofrequency ablation (RFA) is a widely used interventional thermal treatment procedure for diseases such as liver cancer. RFA is based on the application of alternating current inducing ionic agitation in the tissue, resulting in heating and irreversible changes such as protein denaturation and melting of lipid bilayer leading to cell death. One of the major advantages of RFA is that it can be performed in a minimally invasive way, enabling the treatment of non-resectable tumors. However, the minimally invasive nature of the procedure also makes the monitoring of the treatment a challenging one.

Interventional RFA procedures are performed under image guidance. Computed tomography (CT) and ultrasound imaging are commonly used for image guidance. ${ }^{1}$ Real-time monitoring of thermal treatment is performed by observing the temperature at the tip of the RFA electrode and the bubble formation in the treated region with ultrasound imaging. These techniques work well when the thermal conduction in tissue is uniform. However, carbonization around the electrode and the presence of blood vessels can cause non-uniform heating, resulting in incomplete treatment of tissue. ${ }^{2-4}$ This incomplete treatment results in local recurrence of the tumor. Specifically for liver tumors, local recurrence after RFA procedures has reported being as high as $40 \% .^{5}$ The efficiency of RFA procedure can be improved and complete eradication of the diseased tissue is possible with real-time feedback and controlling the RF power. ${ }^{4}$ Thus, there is a need for a new technology that can

Further author information:

K. J. Francis.: E-mail: f.kalloorjoseph@utwente.nl, Telephone: +31534891559

Multiscale Imaging and Spectroscopy, edited by Paul J. Campagnola, Kristen C. Maitland,

Darren M. Roblyer, Proc. of SPIE Vol. 11216, 112160H · (c) 2020 SPIE

CCC code: $1605-7422 / 20 / \$ 21 \cdot$ doi: $10.1117 / 12.2546042$

Proc. of SPIE Vol. $11216112160 \mathrm{H}-1$

Downloaded From: https://www.spiedigitallibrary.org/conference-proceedings-of-spie on 31 Mar 2020 
accurately monitor the thermal treatment. Interestingly, there is a considerable difference in optical properties between native and coagulated tissue. Hence, optical methods can potentially be used for real-time treatment monitoring.

A logical first step in this direction would be to quantify and understand the nature of the changes that the optical properties of the tissue undergo with thermal treatment. The optical properties of biological tissue can be assessed using optical instruments based on continuous-wave, ${ }^{6}$ time-domain or frequency-domain. Of these, time-domain diffuse optics holds unique advantages such as higher penetration depth, better information content and the intrinsic ability to decouple absorption and scattering effects from a single measurement. ${ }^{7,8}$ Moreover, time domain, broadband instrument provides information regarding the tissue constituent concentrations and tissue structure, which could be of great value in clinical studies.

In this work, we report the use of time-resolved diffuse optical spectroscopy (TR-DOS) over a broad range of wavelengths $(650-1100 \mathrm{~nm})$ to monitor changes in optical properties of biological tissue with RF-based thermal treatment. ${ }^{7}$ We present the optical properties of bovine liver tissue during thermal treatment using RFA. We demonstrate the capability of the system to provide real-time changes in absorption and scattering spectra. We present seven key features in the optical properties of the tissue during thermal treatment. We also compare optical properties with normal treatment and overtreatment of the tissue. Additionally, we measured the reversibility of the observed features while cooling the tissue back to the room temperature.

\section{MATERIALS AND METHODS}

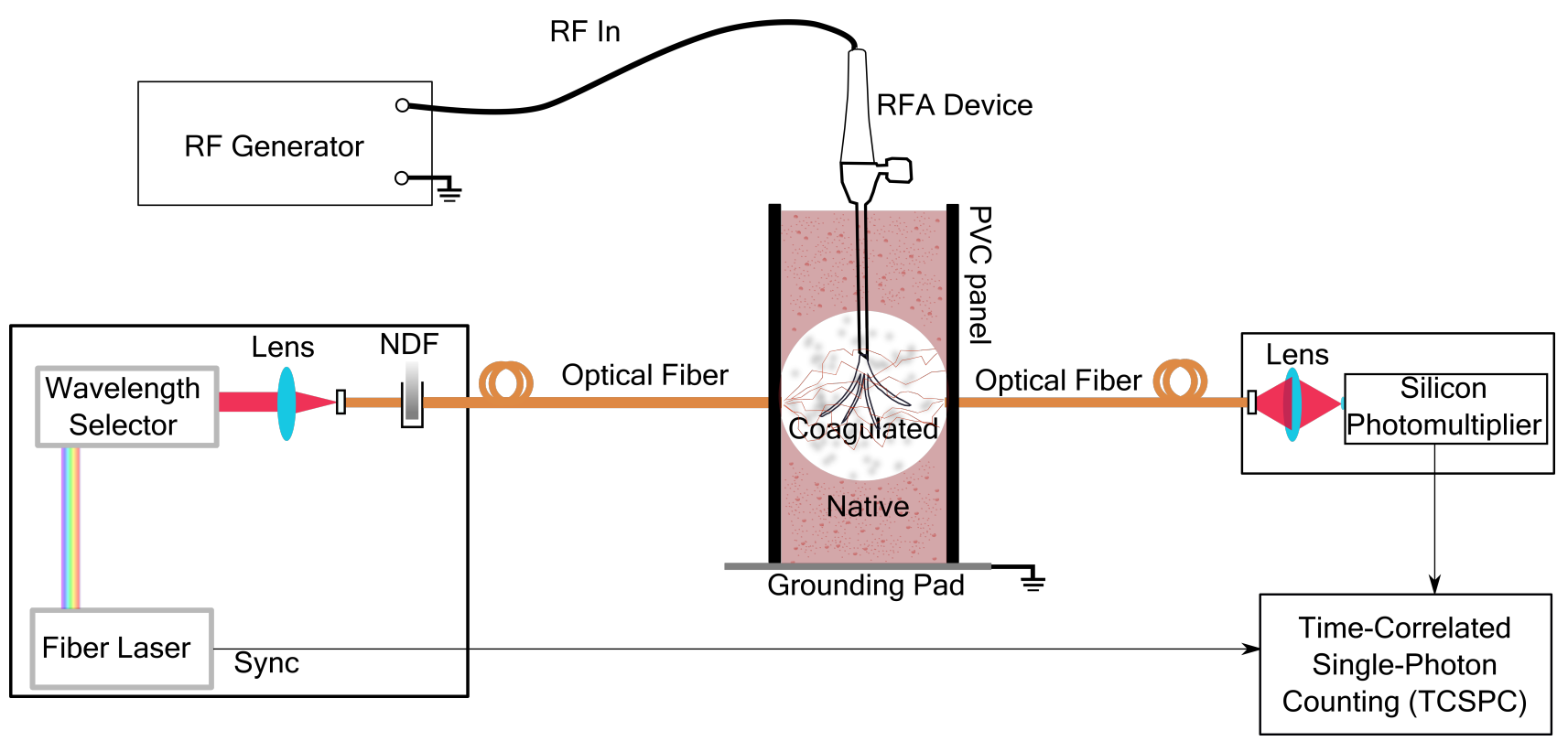

Figure 1. Experimental setup for measuring real-time optical properties of tissue during the radio-frequency ablation procedure. Time-resolved diffuse optical spectroscopy system in a transmittance mode measuring optical properties of the coagulation zone.

The goal was to measure the optical properties of the tissue during the thermal treatment. We have developed an experimental setup that combines a clinical RFA system and a time-resolved diffuse optical spectroscopic system as shown in Fig. 1.

A clinical RFA system (Angiodynamics, USA) was used in this study. The RF generator (1500X) operating at $460 \mathrm{kHz}$ was used with an RFA device (Starburst XL) having 5 electrodes. The dispersive electrode pad (Angiodynamics, USA) for grounding was attached on an aluminum plate and the tissue was placed on top of it as shown in Fig. 1. Black PVC panels were used to support the tissue.

The diffuse optical spectroscope used in this work consists of a broadband $(450-1750 \mathrm{~nm})$ fiber laser and a wavelength selector at the source end, a silicon photomultiplier (Excelitas Technologies) and a time-correlated 
single-photon counting (TCSPC) card at the detector side with a PC to acquire the data and retrieve optical properties from the measurement. Light from the source was coupled into an optical fiber $(1 \mathrm{~mm}$ step indexed fiber (Thorlabs, USA)) with a lens system. An adaptive trimmer with neutral density filters were used to attenuate the intensity of light delivered into the tissue. Measurements were performed in a transmittance geometry, with the fibers placed through the PVC panels. The detector fiber was also placed in a similar fashion aligned to the source fiber and the center of the ablation zone. Back PVC panels were used to avoid any stray light entering into the measurement. The temporal photon count from the TCSPC was used to extract optical properties with a Monte Carlo based light propagation model.

Although we have measured optical properties of the brain, muscle, heart and liver, we limit our results to liver tissue in this article. The tissue was obtained from a local butcher and immediately stored at $4^{0} \mathrm{C}$ in vacuum-sealed plastic bags. Thin slabs of tissue having a thickness of $1 \mathrm{~cm}$ were extracted from the whole liver for the experiment. The measurements were repeated on different samples to check the consistency of the obtained optical properties.

For normal RFA treatment of the tissue, we have selected $70^{\circ} \mathrm{C}$ with $150 \mathrm{~W}$ power delivered for 10 minutes. For overtreatment a temperature of $105^{0} \mathrm{C}$ was applied for 10 minutes. To achieve the target temperature, the system took approximately 3 minutes, followed by 10 minutes of treatment. The spectroscopic measurement for a complete spectrum $650-1100 \mathrm{~nm}$ with a step of $10 \mathrm{~nm}$ took an average of 1 minute.

\section{RESULTS AND DISCUSSION}

Figure 2 shows the optical absorption and reduced scattering spectra of bovine liver tissue during thermal treatment. Figure $2 \mathrm{a}$ and $\mathrm{b}$ are spectra corresponding to thermal treatment with $70^{\circ} \mathrm{C}$ and Figure $2 \mathrm{c}$ and $\mathrm{d}$ are treatment using $105^{\circ} \mathrm{C}$. Treatment with $70^{\circ} \mathrm{C}$ is considered as normal treatment and with $105^{0} \mathrm{C}$ as overtreatment. There are seven key changes we can observe with thermal treatment as following.

1. There is an overall decrease in absorption from native tissue to ablated tissue which can be observed in Fig. 2 a and c.

2. An increase in scattering with thermal treatment as shown in Fig. $2 \mathrm{~b}$ and d.

3. Overtreatment of tissue with $105^{0} \mathrm{C}$ resulted in two changes compared to treatment with $70^{0} \mathrm{C}$. (i) An increase in absorption in the initial part of the spectrum until $910 \mathrm{~nm}$ and (ii) an overall decrease in scattering.

4. Thermal treatment resulted in red-shifting of the hemoglobin peak (around $750 \mathrm{~nm}$ ). This is indicated with a red arrow in Fig. 2 a and c. Redshift is more prominent with overtreatment.

5. Thermal treatment of tissue also resulted in a blue-shifting of the water peak (around $980 \mathrm{~nm}$ ). This is indicated with a blue arrow in Fig. 2 a and c. No considerable difference was observed in the blueshift between normal and overtreatment.

6. A new peak appeared in the absorption spectrum around $840 \mathrm{~nm}$ with thermal treatment as shown in Fig. $2 \mathrm{a}$ and $\mathrm{c}$.

7. A new valley appeared in the absorption spectrum around $920 \mathrm{~nm}$ as in Fig. 2 a and c.

Water is one of the major tissue components and thermal treatment results in evaporation of water and dehydration of the tissue. This reduction in water can result in a decrease in absorption and an increase in scattering. Overall $60-70 \%$ decrease in water absorption peak was observed with heating. The size of the scatterers and their density changes with dehydration. ${ }^{9}$ Additionally, the denaturation of the proteins result in aggregate structures. ${ }^{10}$ These factors result in an increase in scattering. ${ }^{9,} 10$ Another major change in the absorption spectrum is around the hemoglobin peak. A decrease in optical absorption for hemoglobin with increasing temperature was previously reported, which being attributed to the change in different spin states of the iron atom. ${ }^{11,12}$ Our observation of the decrease in hemoglobin peak was also in line with the previous 

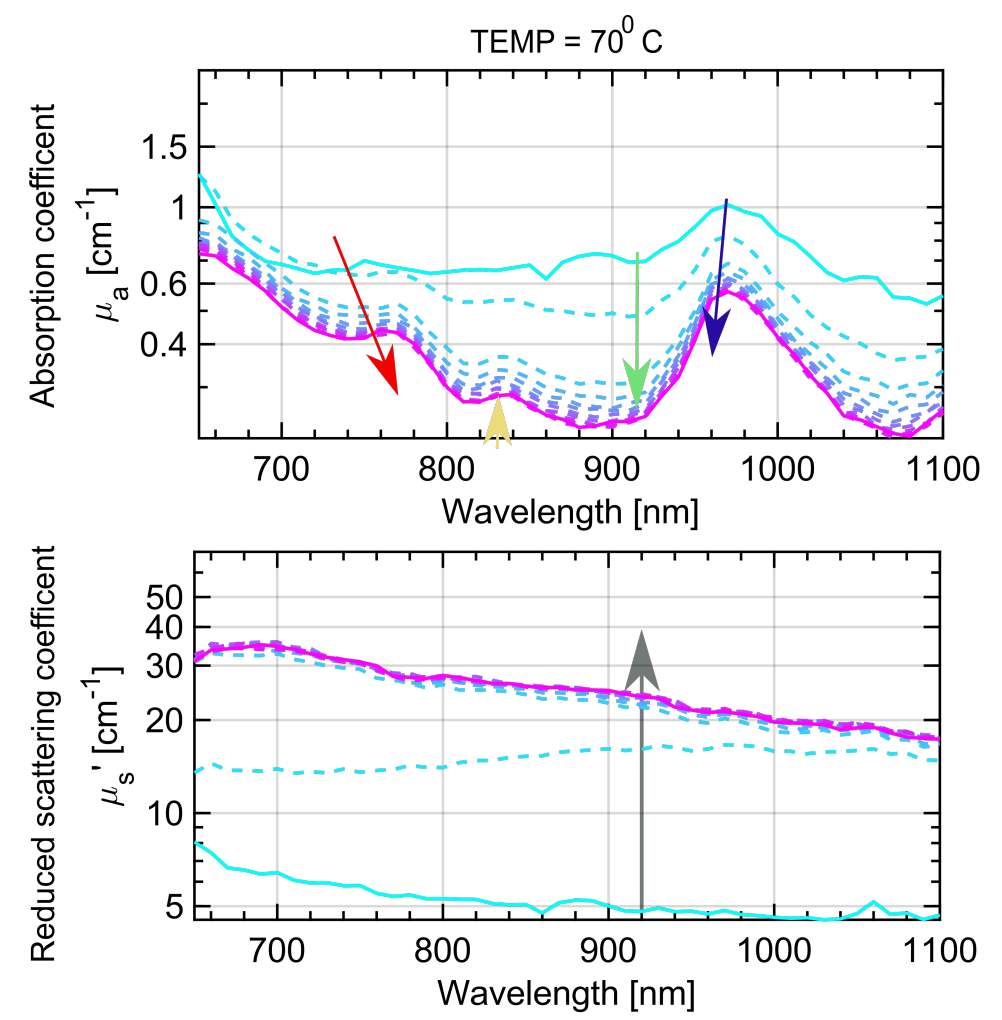

$$
\begin{aligned}
& - \text { Start } \\
& ---1 \mathrm{~min} \\
& ---2 \mathrm{~min} \\
& ---3 \mathrm{~min} \\
& ---4 \mathrm{~min} \\
& ---5 \mathrm{~min} \\
& ---6 \mathrm{~min} \\
& ---7 \mathrm{~min} \\
& ---8 \mathrm{~min} \\
& ---9 \mathrm{~min} \\
& ---10 \mathrm{~min}
\end{aligned}
$$
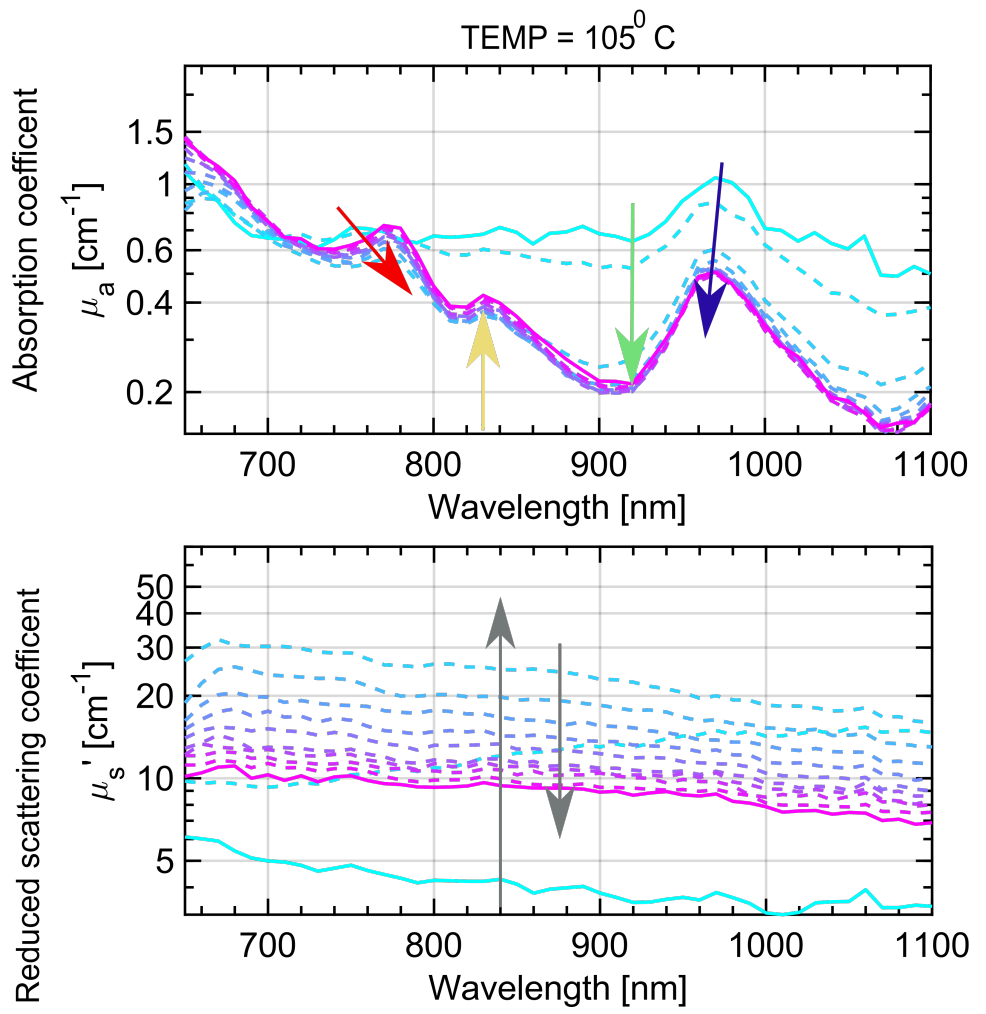

$$
\begin{aligned}
& \rightarrow \text { Red-shift } \\
& \rightarrow \text { Blue-shift } \\
& \rightarrow \text { New valley } \\
& \rightarrow \text { New peak } \\
& \rightarrow \begin{array}{l}
\text { Change in } \\
\text { scattering }
\end{array}
\end{aligned}
$$

Figure 2. Changes in absorption and reduced scattering of bovine liver tissue with radiofrequency ablation using $70^{\circ} \mathrm{C}$ and $105^{\circ} \mathrm{C}$. 
study. However, with overtreatment, an increase in the initial part of the spectrum including the hemoglobin peak has been observed. This increase in absorption followed an exponential decay which might be due to the carbonization of tissue. ${ }^{10}$ The carbonization of the tissue was also visually verified on the treated samples.

A red-shifting of the hemoglobin peak of $4 \mathrm{~nm}$ was observed in the case of thermal treatment with $70^{0} \mathrm{C}$ and $15 \mathrm{~nm}$ for $105^{0} \mathrm{C}$. Similarly, a blue-shift of $4 \mathrm{~nm}$ was observed for the water absorption peak in the case of $70^{0} \mathrm{C}$ treatment and $5 \mathrm{~nm}$ for $105^{\circ} \mathrm{C}$ treatment. These shifts could be attributed with chemical changes of hemoglobin and water. ${ }^{12}$ The new peak around $840 \mathrm{~nm}$ with thermal treatment was observed consistently in all the samples. However, the origin of the peak is unknown. The valley formed around $920 \mathrm{~nm}$ is due to dehydration of the tissue.

Cooling the treated tissue to room temperature resulted in a reversal of some of the above-mentioned effects. Primarily the reversal was observed around the water peak. The blue shift observed during thermal treatment reversed with a red-shift upon cooling. Additionally, the valley formed on either side of the water peak also reversed partially with cooling. However, the red-shifted hemoglobin peak remained even after cooling.

The key spectral changes in optical absorption and scattering can be used to monitor thermal treatment. Differentiating native, coagulated and overtreated tissue can be of clinical importance. Additionally, if the bulk tissue properties of the tissue under treatment are known, it can also assist imaging techniques such as photoacoustic imaging to differentiate treated tissue volume ${ }^{13-16}$

\section{CONCLUSIONS}

We have reported the key features of thermal treatment on the optical properties of tissue. These key features include changes in optical absorption such as a decrease in absorption, shifting of the hemoglobin and water peak and an increase in reduced scattering. We have also shown that the optical properties can be monitored in real-time during the thermal treatment. Additionally, the effect of overtreatment on optical properties was also studied. Cooling the tissue back to room temperature resulted in the revesing of some of the observed features, especially optical absorption around the water peak.

\section{ACKNOWLEDGMENTS}

We would like to acknowledge funding from the European Union's Horizon 2020, Sklodowska-Curie Innovative Training Networks (ITN-ETN) program, under grant agreement no 675332 BitMap and Laserlab-Europe EUH2020 654148 which allowed successful completion of this research.

\section{REFERENCES}

[1] Crocetti, L., Lencioni, R., DeBeni, S., See, T. C., Della Pina, C., and Bartolozzi, C., "Targeting liver lesions for radiofrequency ablation: an experimental feasibility study using a ct-us fusion imaging system," Investigative radiology 43(1), 33-39 (2008).

[2] Curley, S. A., "Radiofrequency ablation of malignant liver tumors," Annals of Surgical Oncology 10(4), 338-347 (2003).

[3] Pillai, K., Akhter, J., Chua, T. C., Shehata, M., Alzahrani, N., Al-Alem, I., and Morris, D. L., "Heat sink effect on tumor ablation characteristics as observed in monopolar radiofrequency, bipolar radiofrequency, and microwave, using ex vivo calf liver model," Medicine 94(9) (2015).

[4] Liang, H., Peng, Z., Chen, M., Peng, H., Xue, P., Zhang, Y., Zhang, Y., and Li, J., "Efficacy of combining temperature-and power-controlled radiofrequency ablation for malignant liver tumors," Chin J Cancer 29(4), 408-12 (2010).

[5] Chua, J. M. E., Lam, Y. M. P., Tan, B. S., Tay, K. H., Gogna, A., Irani, F. G., Lo, H. G. R., and Too, C. W., "Single-centre retrospective review of risk factors for local tumour progression and complications in radiofrequency ablation of 555 hepatic lesions," Singapore medical journal 60(4), 188 (2019).

[6] Ritz, J.-P., Roggan, A., Isbert, C., Müller, G., Buhr, H. J., and Germer, C.-T., "Optical properties of native and coagulated porcine liver tissue between 400 and $2400 \mathrm{~nm}$," Lasers in Surgery and Medicine: The Official Journal of the American Society for Laser Medicine and Surgery 29(3), 205-212 (2001). 
[7] Sekar, S. K. V., Dalla Mora, A., Bargigia, I., Martinenghi, E., Lindner, C., Farzam, P., Pagliazzi, M., Durduran, T., Taroni, P., Pifferi, A., et al., "Broadband (600-1350 nm) time-resolved diffuse optical spectrometer for clinical use," IEEE Journal of Selected Topics in Quantum Electronics 22(3), 406-414 (2015).

[8] Lanka, P., Francis, K., Kruit, H., Sekar, S. K. V., Farina, A., Cubeddu, R., Manohar, S., and Pifferi, A., "Monitoring radiofrequency ablation of biological tissue using broadband time-resolved diffuse optical spectroscopy," in [European Conference on Biomedical Optics], 11074_94, Optical Society of America (2019).

[9] Nilsson, A. M., Sturesson, C., Liu, D. L., and Andersson-Engels, S., "Changes in spectral shape of tissue optical properties in conjunction with laser-induced thermotherapy," Applied optics 37(7), 1256-1267 (1998).

[10] Jacques, S. L., "Role of tissue optics and pulse duration on tissue effects during high-power laser irradiation," Applied Optics 32(13), 2447-2454 (1993).

[11] Sfareni, R., Boffi, A., Quaresima, V., and Ferrari, M., "Near infrared absorption spectra of human deoxyand oxyhaemoglobin in the temperature range 20-40 c," Biochimica et Biophysica Acta (BBA)-Protein Structure and Molecular Enzymology 1340(2), 165-169 (1997).

[12] Welch, A. J., Van Gemert, M. J., et al., [Optical-thermal response of laser-irradiated tissue], vol. 2, Springer (2011).

[13] Francis, K. J., Rascevska, E., and Manohar, S., "Photoacoustic imaging assisted radiofrequency ablation: Illumination strategies and prospects," in [TENCON 2019-2019 IEEE Region 10 Conference (TENCON)], 118-122, IEEE (2019).

[14] Francis, K. J. and Manohar, S., "Photoacoustic imaging in percutaneous radiofrequency ablation: device guidance and ablation visualization," Physics in Medicine $\& 3$ Biology 64(18), 184001 (2019).

[15] Iskander-Rizk, S., Kruizinga, P., Van Der Steen, A. F., and van Soest, G., "Spectroscopic photoacoustic imaging of radiofrequency ablation in the left atrium," Biomedical optics express 9(3), 1309-1322 (2018).

[16] Özsoy, Ç., Floryan, M., Deán-Ben, X. L., and Razansky, D., "Endocardial irrigated catheter for volumetric optoacoustic mapping of radio-frequency ablation lesion progression," Optics letters 44(23), 5808-5811 (2019). 